\title{
Potencial reprodutivo de Chrysoperla externa (Hagen) (Neuroptera, Chrysopidae) em função do número de indivíduos por unidade de criação
}

\author{
Luis Gustavo Amorim Pessoa ${ }^{1} \&$ Sérgio de Freitas ${ }^{2}$
}

${ }^{1}$ Centro Universitário de Várzea Grande, GPA de Ciências Agrárias e Biológicas, Avenida Dom Orlando Chaves, 1775, Cristo Rei 78118-000, Várzea Grande-MT. gugamorim@yahoo.com.br

${ }^{2}$ Universidade Estadual Paulista "Júlio de Mesquita Filho", Faculdade de Ciências Agrárias e Veterinárias de Jaboticabal, Departamento de Fitossanidade, Via de Acesso Professor Paulo Donato Castellane, s/n, 14884-900 Jaboticabal-SP. serfre@ fcav.unesp.br

\begin{abstract}
Reproductive capacity of Chrysoperla externa (Hagen) (Neuroptera, Chrysopidae) in function of the number of individuals per unit of rearing. This work was carried out to investigate the reproductive potential of Chrysoperla externa subjected to different densities per rearing unit. Adults of the $\mathrm{F}_{4}$ offspring were kept at $25 \pm 1{ }^{\circ} \mathrm{C}, \mathrm{RH}$ $70 \pm 10 \%$ and $12 \mathrm{~h}$ photophase. It was used the following densities per rearing unit $(10 \mathrm{~cm}$ of diameter by $23 \mathrm{~cm}$ of height, and volume of $1650 \mathrm{~cm}^{3}$ ): 1 male: 3 female, 2 males: 6 females, 3 males: 9 females and 4 males: 12 females. It was evaluated the pre-oviposition period, the daily and total oviposition per female and per rearing unit, the percentage of viable and infertile eggs percentage and the exploitation index per female and per rearing unit. The density 4 males: 12 females presented better exploitation when compared to the other densities thus equalizing the low values obtained for the mean and total egg laying per female.
\end{abstract}

KEYWORDS. Green lacewings; mass rearing; predators.

RESUMO. Potencial reprodutivo de Chrysoperla externa (Hagen) (Neuroptera, Chrysopidae) em função do número de indivíduos por unidade de criação. Verificou-se o efeito de diferentes densidades de insetos por unidade de criação sobre o potencial reprodutivo de Chrysoperla externa. Utilizaram-se adultos da geração $\mathrm{F}_{4}$ mantidos a $25 \pm 1^{\circ} \mathrm{C}, 70 \pm 10 \%$ de UR e fotofase de 12 horas. Foram utilizadas as seguintes densidades por unidade de criação $(10 \mathrm{~cm}$ de diâmetro por $23 \mathrm{~cm}$ de altura e volume de $1650 \mathrm{~cm}^{3}$ ): um macho e três fêmeas, dois machos e seis fêmeas, três machos e nove fêmeas e quatro machos e doze fêmeas. Avaliou-se o período de pré-oviposição, a oviposição diária e total por fêmea e por unidade de criação, as porcentagens de ovos viáveis e inférteis e o índice de aproveitamento, calculado por fêmea e por unidade de criação. A densidade quatro machos e doze fêmeas apresentou melhor aproveitamento da unidade de criação, compensando as reduções observadas nos valores de postura média e total por fêmea.

PALAVRAS-CHAVE. Crisopídeos; criação massal; predadores.

A maioria dos insetos pertencentes à ordem Neuroptera é predadora, destacando-se as famílias Chrysopidae e Hemerobiidae como as mais importantes por se alimentarem de diversas pragas agrícolas. Estão presentes em diversos agroecossistemas alimentando-se de vários artrópodes-praga tais como pulgões, cochonilhas, mosca branca, ovos e pequenas lagartas de lepidópteros e ácaros (Agnew et al. 1981; Carvalho \& Souza 2000; Freitas 2001a).

A produção massal e eficiente desses predadores em laboratório depende de fatores extrínsecos e intrínsecos. Dentre os extrínsecos podem ser citadas as técnicas utilizadas para multiplicação dos insetos, materiais empregados, a manipulação das fases de desenvolvimento, o controle de qualidade e os custos de produção. Os intrínsecos estão relacionados à fisiologia do inseto como a adaptabilidade à dieta, o potencial reprodutivo, a fecundidade e a fertilidade (Carvalho \& Souza 2000).

Dentre os aspectos envolvidos na multiplicação massal de insetos destacam-se a proporção sexual e a densidade populacional por unidade de criação como sugerido por Parra $(1994,2002)$. Segundo esse autor o aumento da densidade de insetos por unidade de criação pode acarretar um excesso de feromônio no ambiente, causando confundimento dos machos e, conseqüentemente, diminuição do número de cópulas.

A presença dos machos de crisopídeos nas gaiolas de criação durante todo o período reprodutivo contribui não somente para a fecundação, mas também para o estímulo e comportamento de oviposição, recomendando-se a manutenção de uma proporção sexual de um macho para uma fêmea (1:1) (Carvalho \& Souza 2000). Porém, Pessoa (2005) verificou que a proporção sexual de um macho para três fêmeas (1:3) proporcionou um desempenho reprodutivo semelhante a 1:1 e foi superior as demais proporções testadas (1:2, 1:4 e 1:5), para a espécie Chrysoperla externa (Hagen, 1861). Assim, densidades de insetos por unidade de criação, utilizando a proporção 1:3 podem ser testadas visando sua aplicação prática para fins de multiplicação massal dessa espécie de crisopídeo.

Alguns trabalhos têm estudado a melhor densidade de crisopídeos por unidade de criação, porém utilizando a proporção sexual de um macho e uma fêmea (Ferreira 1996).

Assim, o presente trabalho teve por objetivo verificar o 
efeito de diferentes densidades de insetos e por unidade de criação, para a espécie Chrysoperla externa, para fins de criação massal.

\section{MATERIALE MÉTODOS}

Adultos de crisopídeos foram coletados em seringal localizado na Fazenda Escola de Ensino e Pesquisa da Universidade Estadual Paulista "Júlio de Mesquita Filho", Faculdade de Ciências Agrárias e Veterinárias de JaboticabalSP, sendo levados ao laboratório onde, após triagem e identificação, adultos de C. externa foram acondicionados em gaiolas de cloreto de polivinila (PVC). A partir da criação estoque os crisopídeos foram multiplicados e criados em laboratório segundo metodologia proposta por Freitas (2001b), sendo utilizados insetos da quarta geração para montagem dos bioensaios.

Adultos recém-emergidos foram separados por sexo e acondicionados em gaiolas de PVC de $10 \mathrm{~cm}$ de diâmetro por $23 \mathrm{~cm}$ de altura e volume de $1650 \mathrm{~cm}^{3}$, os quais receberam alimentação composta de lêvedo de cerveja e mel, em partes iguais. Foram utilizados quatro tratamentos, os quais consistiram das seguintes proporções sexuais por unidade de criação: um macho e três fêmeas (1:3), dois machos e seis fêmeas (2:6), três machos e nove fêmeas (3:9) e quatro machos e doze fêmeas (4:12). Essa proporção sexual (um macho e três fêmeas) foi determinada em ensaio anterior como a que proporcionou melhor desempenho reprodutivo de C. externa (Pessoa 2005).

O período de avaliação foi de 60 dias e o experimento foi conduzido em sala climatizada a $25 \pm 1^{\circ} \mathrm{C}, 70 \pm 10 \%$ de UR e fotofase de 12 horas.

Foi avaliado o período de pré-oviposição, a oviposição diária e total por fêmea e por unidade de criação, bem como as porcentagens de ovos viáveis e inférteis. A viabilidade e a porcentagem de ovos inférteis foram avaliadas semanalmente, retirando-se uma amostra de trinta ovos de cada gaiola até a última semana de avaliação do experimento, acondicionandoos em placas de teste ELISA (enzime linked immunosorbent assay), as quais foram vedadas com PVC laminado. Foram considerados viáveis aqueles onde houve eclosão da larva.
Além desses parâmetros, também foi utilizado o índice de aproveitamento (IA), o qual leva em consideração a oviposição total, a viabilidade média dos ovos e o período de oviposição (Pessoa et al. 2004). Segundo esses autores, a utilização desse índice permite avaliar o número de ovos viáveis produzidos diariamente por cada fêmea e por cada unidade de criação, podendo ser mais eficiente que a avaliação separadamente dos parâmetros oviposição total e viabilidade média dos ovos. Foram utilizadas nove repetições por tratamento, cada uma constituída por uma unidade de criação, em delineamento inteiramente casualizado.

Os dados referentes à duração do período de préoviposição, oviposição diária e total por fêmea e por unidade de criação, e o IA por fêmea e por unidade de criação foram transformados para $(x+0,5)^{1 / 2}$. Aqueles referentes aos valores das porcentagens de ovos viáveis e inférteis foram transformados para arco-seno $(\mathrm{x} / 100)^{1 / 2}$. Efetuou-se a análise de variância e o teste de comparação de médias de Tukey a 5\% de probabilidade.

\section{RESULTADOS EDISCUSSÃO}

Período de pré oviposição, postura média e postura total por fêmea. A duração do período de pré-oviposição não apresentou diferenças significativas entre os tratamentos variando de 3,4 a 4,6 dias (Tabela I). Esses resultados assemelham-se aos encontrados por Ribeiro \& Carvalho (1991), Ribeiro et al. (1993), Figueira et al. (2002) e Santos et al. (2003), os quais estudaram $C$. externa utilizando apenas um casal por unidade de criação.

Verificou-se uma diminuição nos valores observados para postura média e total por fêmea em função do aumento do número de insetos por unidade de criação. Aquelas que continham quatro machos e doze fêmeas apresentaram os valores desses parâmetros significativamente menores em relação àquelas que continham um macho e três fêmeas e dois machos e seis fêmeas (Tabela I). De acordo com Chapman (1998), a espermatogênese ocorre uma única vez para algumas espécies de insetos e assim a redução no número de ovos, verificada em função do aumento do número de indivíduos por unidade de criação, pode ser explicada pelos efeitos

Tabela I. Período de pré-oviposição e postura diária por fêmea e por unidade de criação de Chrysoperla externa, em função do número de insetos por unidade de criação. ${ }^{(1)}$

\begin{tabular}{clllll}
\hline $\begin{array}{c}\text { Tratamentos } \\
\left(\sigma^{\star}: \text { o }\right)\end{array}$ & $\begin{array}{c}\text { Pré-oviposição } \\
(\text { dias })^{(2)(3)}\end{array}$ & $\begin{array}{c}\text { Postura média por } \\
\text { fêmea }^{(2)(3)}\end{array}$ & $\begin{array}{c}\text { Postura total por } \\
\text { fêmea }^{(2)(3)}\end{array}$ & $\begin{array}{c}\text { Postura média por } \\
\text { unidade de criação(2)(3) }\end{array}$ & $\begin{array}{c}\text { Postura total por } \\
\text { unidade de criação }\end{array}$ \\
\hline $1: 3$ & $3,9 \pm 0,16 \mathrm{a}$ & $10,7 \pm 0,51 \mathrm{a}$ & $612,8 \pm 27,60 \mathrm{a}$ & $27,9 \pm 1,57 \mathrm{~d}$ & $1680,5 \pm 118,54 \mathrm{~d}$ \\
$2: 6$ & $4,5 \pm 0,33 \mathrm{a}$ & $10,4 \pm 0,31 \mathrm{ab}$ & $608,9 \pm 18,29 \mathrm{a}$ & $55,8 \pm 1,49 \mathrm{c}$ & $3239,4 \pm 86,49 \mathrm{c}$ \\
$3: 9$ & $3,4 \pm 0,37 \mathrm{a}$ & $9,1 \pm 0,34 \mathrm{bc}$ & $535,6 \pm 20,38 \mathrm{ab}$ & $73,8 \pm 3,02 \mathrm{~b}$ & $4288 \pm 175,67 \mathrm{~b}$ \\
$4: 12$ & $4,6 \pm 0,33 \mathrm{a}$ & $8,2 \pm 0,26 \mathrm{c}$ & $496,9 \pm 15,82 \mathrm{~b}$ & $93,2 \pm 3,63 \mathrm{a}$ & $5412 \pm 210,60 \mathrm{a}$ \\
\hline DMS & $1,22^{\mathrm{NS}}$ & $1,43^{*}$ & $80,47 *$ & $10,27 *$ & $596,13^{*}$ \\
CV $(\%)$ & 10,11 & 5,32 & 5,43 & 6,01 & 6,43 \\
\hline
\end{tabular}

${ }^{(1)}$ Médias seguidas pela mesma letra na coluna não diferem significativamente entre si pelo teste de Tukey $(\mathrm{P}<0,05)$.

(2)Para análise os dados foram transformados em $(x+0,5)^{1 / 2}$.

${ }^{(3)}$ Número de observações $=9$. 
negativos associados ao aumento da densidade como menor transferência de espermatozóides às fêmeas e redução do espaço da gaiola por fêmea como constatado por Karelin et al. (1989) e Araújo \& Bichão (1990). Também, segundo Parra (1994), o aumento da densidade de insetos por unidade de criação pode acarretar um excesso de feromônio no ambiente, causando confundimento dos machos e, conseqüentemente, diminuição do número de cópulas.

Postura média e total por unidade de criação. As produções média e total de ovos por unidade de criação apresentaram diferenças significativas em função do número de insetos (Tabela I). Verificou-se que a maior densidade de insetos apresentou valores significativamente maiores em relação às demais.

Os valores observados para as produções média e total de ovos, na densidade quatro machos e doze fêmeas foram de 1,$3 ; 1,7$ e 3,3 e 1,3; 1,7 e 3,2 vezes maiores que as densidades três machos e nove fêmeas, dois machos e seis fêmeas e um macho e três fêmeas, respectivamente. Esses resultados indicam que houve um melhor aproveitamento do espaço da unidade de criação para produção de ovos uma vez que as fêmeas dispunham de um menor espaço físico na maior densidade de insetos $\left(103,1 \mathrm{~cm}^{3}\right.$ para a densidade quatro machos e doze fêmeas; $137,5 \mathrm{~cm}^{3}$ para a densidade três machos e nove fêmeas; $206,2 \mathrm{~cm}^{3}$ para a densidade dois machos e seis fêmeas; $412,5 \mathrm{~cm}^{3}$ para a densidade de um macho e três fêmeas).

Esses resultados são superiores aos encontrados por Ferreira (1996), que testando diferentes unidades de criação para adultos de C. externa encontrou, para insetos criados na unidade padrão (tubo de PVC de $10 \mathrm{~cm}$ de diâmetro por $23 \mathrm{~cm}$ de altura e $1650 \mathrm{~cm}^{3}$ ), um total de 1692,$0 ; 753,2$ e 291 ovos e uma média de 3,4; 3,0 e 5,8 ovos com espaço físico por fêmea de $82,5 \mathrm{~cm}^{3}, 165,0 \mathrm{~cm}^{3}$ e $825,0 \mathrm{~cm}^{3}$ para as densidades de dez, cinco e um casal por unidade de criação.

Porcentagem de ovos viáveis e inférteis e índice de aproveitamento por fêmea e por unidade de criação. Apenas a densidade de dois machos e seis fêmeas apresentou redução significativa na porcentagem de ovos viáveis em relação a um macho e três fêmeas. As maiores densidades (três machos e nove fêmeas e quatro machos e doze fêmeas) não apresentaram efeitos negativos do aumento de indivíduos na unidade de criação para esse parâmetro (Tabela II). Também não houve efeito do aumento do número de insetos sobre a porcentagem de ovos inférteis.

Todos os valores de porcentagem de ovos viáveis e inférteis assemelham-se aos encontrados por vários autores utilizando a proporção sexual de um macho e uma fêmea de $C$. externa e utilizando apenas um casal por unidade de criação (Ribeiro \& Carvalho 1991; Ribeiro et al. 1993; Velloso et al. 1999; Ulhôa et al. 2002; Carvalho et al. 2003; Macedo et al. 2003). Dessa forma, verificou-se que a fertilidade dos ovos independe do número de fêmeas por unidade de criação e que não houve confundimento dos machos pela possível saturação do ambiente com feromônio sexual em função do aumento do número de fêmeas, como sugerido por Parra (1994).

Não ocorreram diferenças significativas entre os valores do índice de aproveitamento por fêmea em função do aumento da densidade de insetos (Tabela II). Mesmo sendo encontrados valores significativamente menores para as posturas médias por fêmea (Tabela I), o número médio de ovos viáveis produzidos por cada fêmea (dado por esse índice) não apresentou diferenças entre os tratamentos sendo, nesse caso, mais eficiente que a avaliação em separado dos parâmetros que compõem esse índice. Porém, ao se avaliar o índice de aproveitamento por unidade de criação, verificou-se que a densidade de quatro machos e doze fêmeas apresentou valor significativamente maior em relação aos demais valores $(81,5)$. Este fato pode ser considerado como esperado, uma vez que o macho de C. externa é capaz de copular com mais de uma fêmea (Pessoa 2005) e o aumento destas por unidade de criação implica em maior produção de ovos e, conseqüentemente, maior valor será observado para esse parâmetro.

Verifica-se que, de maneira geral, a densidade quatro machos e doze fêmeas apresentou melhor desempenho em relação às demais, compensando os menores valores obtidos para a postura média e total por fêmea, com um melhor aproveitamento do espaço existente na unidade de criação. Os resultados obtidos para a produção total de ovos por gaiola demonstram a melhor utilização da unidade de criação padrão (10 $\mathrm{cm}$ de diâmetro por $23 \mathrm{~cm}$ de altura), sendo superiores aos encontrados por Ferreira (1996), o qual recomendou a

Tabela II. Porcentagem de ovos viáveis e inférteis e índice de aproveitamento por fêmea e por unidade de criação de Chrysoperla externa ${ }^{(1)}$.

\begin{tabular}{|c|c|c|c|c|}
\hline $\begin{array}{l}\text { Tratamentos } \\
\left(0^{x}: \text { o }\right)\end{array}$ & $\begin{array}{l}\text { Porcentagem de } \\
\text { ovos viáveis }^{(2)(4)}\end{array}$ & $\begin{array}{l}\text { Porcentagem de } \\
\text { ovos inférteis }^{(2)(4)}\end{array}$ & $\begin{array}{l}\text { Índice de aproveitamento } \\
\text { por fêmea }\end{array}$ & $\begin{array}{l}\text { Índice de aproveitamento por } \\
\text { unidade de criação } \\
{ }^{(3)(4)}\end{array}$ \\
\hline $1: 3$ & $95,7 \pm 1,46 \mathrm{a}$ & $1,4 \pm 1,17 \mathrm{a}$ & $10,2 \pm 0,55 \mathrm{a}$ & $28,1 \pm 2,06 \mathrm{~d}$ \\
\hline $2: 6$ & $85,2 \pm 2,97 b$ & $2,2 \pm 0,88 \mathrm{a}$ & $8,7 \pm 0,49 a$ & $46,8 \pm 2,22 \mathrm{c}$ \\
\hline $3: 9$ & $88,6 \pm 2,71 \mathrm{ab}$ & $1,7 \pm 0,41 \mathrm{a}$ & $9,1 \pm 0,42 \mathrm{a}$ & $64,5 \pm 3,73 b$ \\
\hline $4: 12$ & $87,8 \pm 2,06 \mathrm{ab}$ & $1,1 \pm 0,38 \mathrm{a}$ & $9,1 \pm 0,37 \mathrm{a}$ & $81,5 \pm 4,89 a$ \\
\hline DMS & $8,50^{*}$ & $5,52^{\mathrm{NS}}$ & $1,79^{\mathrm{NS}}$ & $13,17 *$ \\
\hline $\mathrm{CV}(\%)$ & 9,31 & 59,98 & 7,11 & 8,71 \\
\hline
\end{tabular}

\footnotetext{
${ }^{(1)}$ Médias seguidas pela mesma letra na coluna não diferem significativamente entre si pelo teste de Tukey $(\mathrm{P}<0,05)$.

(2) Para análise os dados foram transformados em arco-seno $(\mathrm{x} / 100)^{1 / 2}$.

${ }^{(3)}$ Para análise os dados foram transformados em $(x+0,5)^{1 / 2}$.

${ }^{(4)}$ Número de observações $=9$.
} 
densidade de 10 casais por proporcionar melhor fecundidade por unidade de criação.

A diminuição do total de insetos por unidade de criação pode ter proporcionado menor estresse às fêmeas, pelo aumento do espaço físico na gaiola $\left(103,1 \mathrm{~cm}^{3}\right)$ em comparação aos estudos realizados por Ferreira (1996), onde cada fêmea dispunha de $82,5 \mathrm{~cm}^{3}$.

Nas condições estudadas, verifica-se que o aumento da densidade de insetos por unidade de criação implica na redução da postura média e total por fêmea, porém acarreta maior produção média e total por unidade de criação, refletindo na melhor utilização das mesmas, recomendando-se a densidade de quatro machos e doze fêmeas para unidade de criação de $10 \mathrm{~cm}$ de diâmetro por $23 \mathrm{~cm}$ de altura.

Densidades superiores a recomendada promoverão menor disponibilidade de espaço físico nas unidades de criação para os insetos, podendo interferir de forma negativa sobre o desempenho reprodutivo dos mesmos.

\section{REFERÊNCIAS}

Agnew, C. W.; W. L. Sterling \& D. A. Dean. 1981. Notes on the Chrysopidae and Hemerobiidae of eastern Texas with keys for their identification. The Southwestern Entomologist 4: 1-20.

Araujo, J. \& M. H. Bichão. 1990. Biotecnologia de produção de Chrysoperla carnea (Stephens) (Neuroptera: Chrysopidae). Boletin de Sanidad Vegetal Plagas 16: 113-118.

Carvalho, C. F. \& B. Souza. 2000. Métodos de criação e produção de crisopídeos, p. 91-109. In: V. H. P. Bueno (ed.). Controle biológico de pragas: produção massal e controle de qualidade. Lavras: UFLA, 207 p.

Carvalho, G. A.; D. Bezerra; B. Souza \& C. F. Carvalho. 2003. Efeitos de inseticidas usados na cultura do algodoeiro sobre Chrysoperla externa (Hagen) (Neuroptera: Chrysopidae). Neotropical Entomology 32: 699-706.

Chapman, R. F. 1998. Reproductive system: male, p. 268-294 In: R. F. Chapman (ed). The insects: structure and fuction. Cambridge: Cambridge University, 770 p.

Ferreira, R. J. 1996. Técnicas para produção massal de crisopídeos (Neuroptera: Chrysopidae). Dissertação (Mestrado em Agronomia/Entomologia) - Faculdade de Ciências Agrárias e Veterinárias - Universidade Estadual Paulista, Jaboticabal. 115 p.

Figueira, L. K.; F. M. Lara \& I. Cruz. 2002. Efeito de genótipos de sorgo sobre o predador Chrysoperla externa (Hagen) (Neuroptera:
Chrysopidae) alimentado com Schizaphis graminum (Rondani) (Hemiptera: Aphididae). Neotropical Entomology 31: 133-139.

Freitas, S. de. 2001a. O uso de crisopídeos no controle biológico de pragas. Jaboticabal: Funep, $66 \mathrm{p}$.

Freitas, S. de. 2001b. Criação de crisopídeos (bicho lixeiro) em laboratório. Jaboticabal: Funep, $20 \mathrm{p}$

Karelin, V. D.; T. N. Yakouchuk \& V. P. Danu. 1989. Development of techniques for commercial production of the common green lacewing Chrysopa carnea (Neuroptera: Chrysopidae). Acta Entomologica Fennica 53: 31-35.

Macedo, L. P. M.; B. Souza; C. F. Carvalho \& C. C. Ecole. 2003. Influência do fotoperíodo no desenvolvimento e na reprodução de Chrysoperla externa (Hagen) (Neuroptera: Chrysopidae). Neotropical Entomology 32: 91-96.

Parra, J. R. P. 1994. Técnicas de criação de insetos para programas de controle biológico. 2 ed. Piracicaba: ESALQ, 196 p.

Parra, J. R. P. 2002. Criação massal de inimigos naturais, p. 143-164. In: Parra, J. R. P; P. S. M. Botelho; B. S. Corrêa-ferreira \& J. M. S Bento. (eds.). Controle biológico no Brasil: parasitóides e predadores. São Paulo: Manole, 635 p.

Pessoa, L. G. A.; S. de Freitas; S. Gardim \& K. C. Rodrigues. 2004. Potencial reprodutivo de adultos de Chrysoperla raimundoi Freitas e Penny (Neuroptera: Chrysopidae) em função da alimentação larval. Arquivos do Instituto Biológico 71: 519-521.

Pessoa, L. G. A. 2005. Fatores que afetam o potencial reprodutivo de Chrysoperla externa (Hagen) (Neuroptera: Chrysopidae) Tese (Doutorado em Agronomia/Entomologia) - Faculdade de Ciências Agrárias e Veterinárias - Universidade Estadual Paulista, Jaboticabal. 55p.

Ribeiro, M. J. \& C. F. Carvalho. 1991. Aspectos biológicos de Chrysoperla externa (Hagen, 1861) (Neuroptera: Chrysopidae) em diferentes condições de acasalamento. Revista Brasileira de Entomologia 35: 423-427.

Ribeiro, M. J.; C. F. Carvalho \& J. C. Matioli. 1993. Biologia de adultos de Chrysoperla externa (Hagen, 1861) (Neuroptera: Chrysopidae) em diferentes dietas artificiais. Ciência e Prática 17: 120-130.

Santos, T. M. dos; A. L. B. Boiça Junior \& J. J. Soares. 2003. Influência de tricomas do algodoeiro sobre os aspectos biológicos e capacidade predatória de Chrysoperla externa (Hagen) alimentada com Aphis gossypii Glover. Bragantia 62: 243-254.

Veloso, A. H. P. P.; R. L. O. Rigitano; G. A. Carvalho \& C. F. Carvalho. 1999. Efeitos de compostos reguladores de crescimento de insetos sobre larvas e adultos de Chrysoperla externa (Hagen, 1861) (Neuroptera: Chrysopidae). Revista Ciência e Agrotecnologia, 23: $96-101$.

Ulhôa, J. L. R.; G. A. Carvalho; C. F. Carvalho \& B. Souza. 2002. Ação de inseticidas recomendados para o controle do curuquerê-doalgodoeiro para pupas e adultos de Chrysoperla externa (Hagen, 1861) (Neuroptera: Chrysopidae). Revista Ciência e Agrotecnologia Edição especial: 96-101.

Recebido em 16/07/2007; aceito em 27/05/2008 